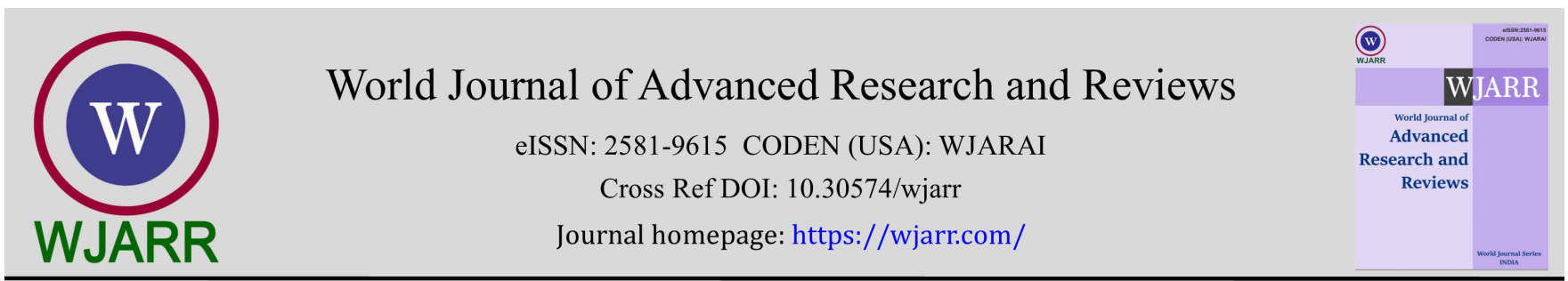

(RESEARCh ARTICLE)

\title{
Assessment of fibrinogen level among Sudanese patient with myocardial infarction in Khartoum City- Sudan
}

\author{
Mona Mahmoud Fadul * and Mahdi H.A Abdalla \\ Department of Hematology, Faculty of Medical Laboratory Sciences, Alneelain University, Khartoum, Sudan.
}

World Journal of Advanced Research and Reviews, 2021, 09(02), 155-158

Publication history: Received on 19 January 2021; revised on 15 February 2021; accepted on 17 February 2021

Article DOI: https://doi.org/10.30574/wjarr.2021.9.2.0066

\begin{abstract}
Fibrinogen has been identified as a major independent risk factor for cardiovascular diseases. Myocardial infarction is cardiomyocyte death as result of a prolonged ischemia. The aim of this study was to determine fibrinogen level in Sudanese patients with myocardial infarction.

A case control study was conducted in AL-Shaab Hospital and Sudan heart center at Khartoum state, Sudan. A total of 100 study participants were enrolled in the study; 50 were myocardial infarction patients and 50 were apparently healthy individuals as control. The blood Samples were collected in $3.2 \%$ trisodium citrate and Fibrinogen level was measured using ready kits principle. The data were analysed by statistical package of social sciences version 21 .
\end{abstract}

The study revealed that fibrinogen level was higher in Myocardial infarction (MI) patients compared with normal individuals. There is a significant strong positive correlation between fibrinogen and Troponin- 1 Level at the 0.05 level.

Keywords: Fibrinogen level; Myocardial infarction; Troponin

\section{Introduction}

Cardiovascular disease remains the leading cause of mortality and morbidity despite the identification of major risk factors and risk reduction strategies. Myocardial infarction (MI) is a relevant cardiovascular worldwide event for morbidity and mortality. In most cases, sudden cardiac death is triggered by ischemia-related ventricular tachyarrhythmia and accounts for $50 \%$ of deaths from cardiovascular disease in developed countries [1]. Clinically, MI is a syndrome that can be recognized by a set of symptoms, chest pain being the hallmark of these symptoms in most cases, supported by biochemical laboratory changes, electrocardiographic (ECG) changes, or finding on imaging modalities able to detect myocardial injury and necrosis. In Sudan the literature about the association of fibrinogen level and myocardial infraction are scared [2]. In the pathogenesis of acute myocardial infarction (MI), common risk factors for atherosclerosis as well as haemostatic factors are important determinants. The development of a first MI is attributed to many contributing factors and is influenced by multiple genetic, environmental and lifestyle factors. Thrombosis is generally accepted as a common pathogenic pathway for the risk of MI and is itself also influenced by several risk factors [3]. Myocardial infarction occurs when myocardial ischemia, a diminished blood supply to the heart, exceeds a critical threshold and overwhelms myocardial cellular repair mechanisms designed to maintain normal operating function and homeostasis [4]. There were many previous studies conducted in Sudan about the association of fibrinogen levels, D-dimer and other coagulation factors with hypertension and other heart disease. A fibrinogen level has been identified as a major independent risk factor for cardiovascular disease and measurement of fibrinogen level may be beneficial to avoid the complication of hypertension [5-8]. The present study aimed to determine the fibrinogen level among Sudanese patients with myocardial infarction in Khartoum.

\footnotetext{
* Corresponding author: Mona Mahmoud Fadul

Department of Hematology, Faculty of Medical Laboratory Sciences, Alneelain University, Khartoum, Sudan.
} 


\section{Material and methods}

A case control study was conducted in AL-Shaab Hospital and Sudan heart center at Khartoum state, Sudan. A total of 100 participants were selected, 50 myocardial infarction patients and 50 apparently healthy individual as control. 1.8 $\mathrm{ml}$ of venous blood was collected from each subject in $3.2 \%$ trisodium citrate (9:1 vol/vol). The samples were centrifuged at $2000 \mathrm{~g}$ for 15 minutes to obtain platelet-poor plasma (PPP). Plasma was separated from cells into plane container. PPP was stored at $\left(-20^{\circ} \mathrm{C}\right)$ till used. Fibrinogen was measured using automatic analyzer (STAGO) with ready kits principle. The principle of the test is that, in the presence of excess thrombin, the clotting time of the plasma is direct proportional with the level of fibrinogen in the plasma. Troponin-1 levels were obtained from patients records. Data analysis was performed using statistical package for social science (SPSS) software version (21). Data was collected using structure questionnaire and direct interview to collect information. Evaluation of patient's data with control data was performed using the t-test. Determination of the correlation between fibrinogen level and Troponin-1 was performed using Spearman correlation test. Results with p-value $<0.05$ were considered as statistically significant.

\section{Results}

The study included 50 myocardial infarction patients and 50 apparently healthy individuals as control, the mean age of cases was $61.1 \pm 11.6$ year.

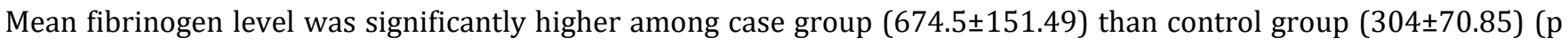
value $=0.000$ ) as shown in table (1).

Table 1 Show the comparison of fibrinogen level between patients and controls

\begin{tabular}{|l|l|l|l|}
\hline & Mean Fibrinogen level mg/dl & STD & P value \\
\hline Patients & 674.5 & 151.49 & \multirow{2}{*}{0.000} \\
\hline Controls & 304 & 70.85 & \\
\hline
\end{tabular}

There was no significant difference in mean fibrinogen level between males and females as shown in table 2 .

Table 2 Show the comparison of fibrinogen level between males and females.

\begin{tabular}{|l|l|l|l|}
\hline & Mean Fibrinogen level mg/dl & STD & P value \\
\hline males & 674.4 & 152.5 & \multirow{2}{*}{0.995} \\
\hline females & 674.7 & 154.2 & \\
\hline
\end{tabular}

Mean Troponin-1 level of the cases was 3.14 \pm 3.692 , there was a significant positive correlation between Troponin-1 and fibrinogen levels (R2 = 0.839 , $\mathrm{p}$ value $=0.019$ ).

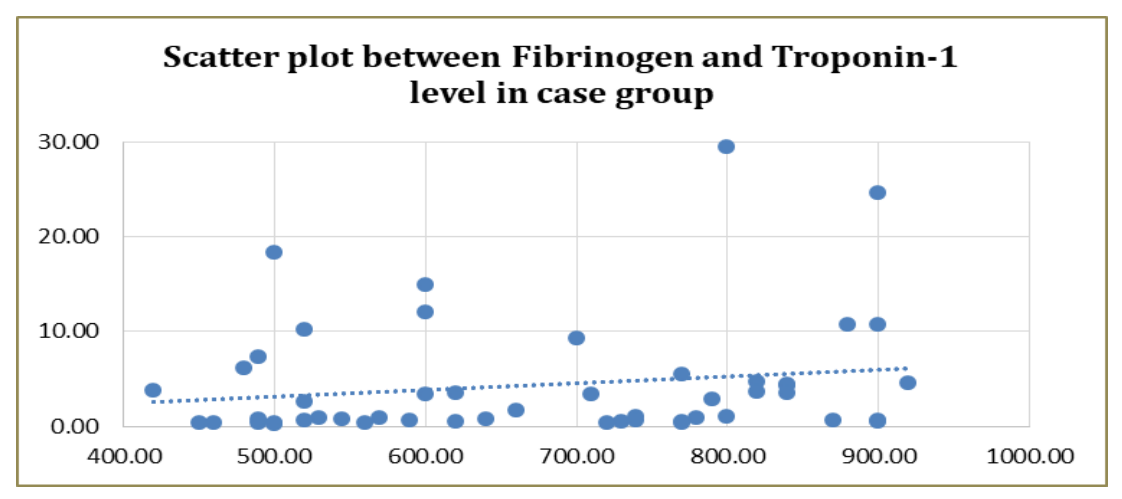

Figure 1 The Fibrinogen and Troponin-1 level among case 


\section{Discussion}

Myocardial infarction is recognized as one of the principal risk factors for cardiovascular disease and may be associated with impaired fibrinolysis [9]. Fibrinogen is a major determinant of blood viscosity, and it is involved in hemostatic and thrombotic pathways. Elevated plasma fibrinogen is implicated in cardiovascular disease. However, it's not clear whether fibrinogen levels predict the development of Myocardial infarction. Our finding demonstrated that, the plasma fibrinogen level was significantly higher in the Myocardial infarction patients than in control group. This result is agreed with several studies conducted among Myocardial infarction patients [10] [11]. Also, this finding is contrary to the findings reported by other workers [12] [13]. Although Sechi et al. didn't observe differences in fibrinogen between Myocardial infarction patients and normal controls, their study demonstrated a strong and independent association between fibrinogen and the presence and severity of Myocardial infarction related damage in different target organs [14].

Our study show that the genders of the patient have no effect on the fibrinogen level, both sexes has same level of fibrinogen.

This finding is in agreement with study done by Anoop et al. found that elevated plasma fibrinogen level was positively associated with prevalent Myocardial infarction both among men and women [15].Another study conducted by Folsom et al and concluded that despite a moderately strong positive association between fibrinogen levels and prevalent Myocardial infarction in both sex-es, there was only a weak positive association between fibrinogen levels and incident Myocardial infarction in men and no association in women. Whether an elevated fibrinogen level is a risk factor for, or a consequence of, Myocardial infarction remains unclear [16]. Our study is limited by the low number of subjects and other thrombotic markers like D-dimer.

\section{Conclusion}

The study concluded that fibrinogen level was higher in MI patient compared with normal individuals, that's mean fibrinogen consider risk factor for myocardial infarction. There's significant strong positive correlation between fibrinogen level and troponin-1 level.

\section{Compliance with ethical standards}

\section{Acknowledgments}

Authors express sincerely thanks to all participants in this study. And especial thanks to all staff of heart center in ALShaab Hospital and Sudan at Khartoum state

\section{Disclosure of conflict of interest}

All the authors hereby disclose no conflict of interest.

\section{References}

[1] Ali NMA, Gameel FEMH, Elsayid M, Babker AMAA. Alterations in D-Dimer, Prothrombin Time and Activated Partial Thromboplastin Time as Thrombogenesis Activity Markers in Patients with Acute Myocardial Infarction. Open Journal of Blood Diseases. 2016; 6: 1-5.

[2] Amsterdam EA, Wenger NK, Brindis RG, Casey DE, Ganiats TG, Holmes DR, Jaffe AS, Jneid H, Kelly RF, Kontos M C, Levine GN, Liebson PR, Mukherjee D, Peterson ED, Sabatine MS, Smalling RW, Zieman SJ. (23 September 2014). "2014 AHA/ACC Guideline for the Management of Patients With Non-ST-Elevation Acute Coronary Syndromes: A Report of the American College of Cardiology/American Heart Association Task Force on Practice. 2014.

[3] Hernandez LM, Blazer DG. Genetic, Environmental, and Personality Determinants of Health Risk Behaviors. The National Academies Press (NAP), USA. 2006.

[4] Li YH, Teng JK, Tsai WC, Tsai LM, Lin LJ, Guo HR, Chen JH. Prognostic Significance of Elevated Hemostatic Markers in Patients with Acute Myocardial Infarction. Journal of the American College of Cardiology. 1999; 33: 1543-1548. 
[5] Ibrahim HMA, Abdalla MHA. D-Dimer Levels in Sudanese Hypertensive Patients. American Journal of Medicine and Medical Sciences. 2014; 4: 92-95.

[6] Eldour, Ahmed Abdalla Agab, et al. Fibrinogen Levels in Hypertensive and Normotensive: A Cross-Sectional Study from El-Obied City, Sudan. Journal of Biosciences and Medicines. 2016; 4(2): 28-32.

[7] Altoum AEA, Ahmed L. Osman, AM Babker. Comparative study of levels of selective oxidative stress markers (malondialdehyde, zinc, and antioxidant vitamins A, E, and C) in ischemic and non-ischemic heart disease patients suffering from type-2 diabetes." Asian J Pharm Clin Res. 2018; 11(8): 508-510.

[8] Ali NM, Gameel FE, Mohieldin Elsayid AM, Babker AA. Original Research Article Influence of anticoagulant therapy in assessment of Fibrinolysis activity in post acute myocardial infarction patients. Sch. Acad. J. Pharm., 2015; 5(1): 14-19.

[9] Thomas A, Kelleher C, Green F, Meade TW, Humphries SE. Variation in the promoter region of the beta-fibrinogen gene is associated with plasma fibrinogen levels in smokers and non-smokers. Thromb Haemost. 1991; 65: 487490.

[10] van't Hooft FM, von Bahr SJ, Silveira A, Iliadou A, Eriksson P, Hamsten A. Two common, functional polymorphisms in the promoter region of the beta-fibrinogen gene contribute to regulation of plasma fibrinogen concentration. Arterioscler Thrombos Vasc Biol. 1999; 19: 3063-3070.

[11] Green F, Hamsten A, Blombäck M, Humphries S. The role of beta-fibrinogen genotype in determining plasma fibrinogen levels in young survivors of myocardial infarction and healthy controls from Sweden. Thromb Haemost. 1993; 70: 915-920.

[12] Scarabin P-Y, Bara L, Ricard S, Poirier O, Cambou JP, Arveiler D, Luc G, Evans AE, Samama MM, Cambien F. Genetic variation at the $\beta$-fibrinogen locus in relation to plasma fibrinogen concentrations and risk of myocardial infarction. The ECTIM Study. Arterioscler Thromb. 1993; 13: 886-891.

[13] Behague I, Poirier O, Nicaud V, Evans A, Arveiler D, Luc G, Cambou J-P, Scarabin P-Y, Bara L, Green F, Cambien F. Beta-fibrinogen gene polymorphisms are associated with plasma fibrinogen and coronary artery disease in patients with myocardial infarction. The ECTIM Study. Circulation. 1996; 93: 440-449.

[14] Tybjaerg-Hansen A, Agerholm-Larsen B, Humphries SE, Abildgaard S, Schnohr P, Nordestgaard BG. A common mutation $(\mathrm{G}-455 \rightarrow \mathrm{A}$ ) in the $\beta$-fibrinogen promoter is an independent predictor of plasma fibrinogen, but not of ischemic heart disease: a study of 9,127 individuals based on the Copenhagen City Heart Study. J Clin Invest. 1997; 99: 3034-3039.

[15] Humphries SE, Ye S, Talmud P, Bara L, Wilhelmsen L, Tiret L. European Atherosclerosis Research Study: genotype at the fibrinogen locus (G-455 $\rightarrow$ A $\beta$-gene) is associated with differences in plasma fibrinogen levels in young men and women from different regions in Europe: evidence for gender-genotype-environment interaction. Arterioscler Thromb Vasc Biol. 1995; 15: 96-104.

[16] Asakawa H, Tokunaga K, Kawakami F. Elevation of fibrinogen and thrombin-antithrombin III complex levels of type 2 diabetes mellitus patients with retinopathy and nephropathy. J Diabetes Complications. 2000; 14: 121126. 